\title{
Determination of Phase Transitions in Gutta-Percha by Differential Thermal Analysis
}

Hillar M. ROOTARE and JOHN M. POWERS

Department of Dental Materials, School of Dentistry, University of Michigan, Ann Arbor, Michigan 48109, USA

Pure gutta-percha was heat-treated in a differential thermal analyzer. The high melting form crystallized on cooling when gutta-percha was heated to $70 \mathrm{C}$ or less. Above $74 C$, crystallization into the low melting form predominated. Either polymorph can be selectively crystallized by control of the heat-treatment temperature before cooling.

J Dent Res 56(12): 1453-1462, December 1977.

Gutta-percha, which occurs naturally as trans1,4-polyisoprene, has been found to exist in at least two crystalline states, a low melting or $\beta$-form and a high melting or $\gamma$-form. ${ }^{1-4}$ Bunn $^{1}$ predicted and Fisher ${ }^{2}$ confirmed by electron diffraction the existence of three configurations $(\alpha, \beta$, and $\gamma)$ of the trans-polyisoprene chain. The $\alpha$-form was observed only in stretched samples of gutta-percha. ${ }^{2}$ Recently, Takahashi et $a 1^{4}$ determined by $x$-ray diffraction that the crystal structure of the $\alpha$-form was identical to that of the $\gamma$-form.

Thermal analysis of experimental and commercial gutta-percha points used in endodontics has demonstrated the presence of up to seven thermal transitions. ${ }^{5-3}$ Further, transition temperatures and penetration were shown to be affected by heat treatment of the samples. ${ }^{6-7}$ The ability to convert gutta-percha from one crystalline form to another by heat treatment may be a useful technique for both the manufacturer of points and the endodontist.

The purpose of this study was to determine

Received for publication September 20, 1976

Accepled for publication March 7, 1977.

*Model 900 , E. I. du Pont de Nemours \& Co., Inc. Instrument

Products Division, Wilmingıon, Del 19898.

†Herman Webber and Co., Inc., Newark, NJ 07102.

tModel XRJ-3000, Philips Electronic Instruments, Mount Vernon, NY 10550 .

\$aake Model FE Consiant Temperalure Circulator, Polyscience Corp., Evansion, Il 60201 .

IModel 160B, Keithley Instruments, Inc., Cleveland, Oh 44139. by differential thermal analysis (DTA) the effect of nonequilibrium heating and cooling on the formation of low and high melting forms of gutta-percha crystallized from the bulk.

\section{Materials and Methods}

A differential thermal analyzer* was used to determine peak temperatures of endotherms on heating and exotherms on cooling of samples of purified gutta-percha. ${ }^{\dagger}$ Small shavings (about 5 $\mathrm{mg}$ ) of the gutta-percha were placed into the sample capillary tube and the sample thermo. couple inserted. Glass beads were used in conjunction with the reference thermocouple. DTA was carried out in air at a heating rate of $20 \mathrm{C}$ per minute. A series of runs was made on the same sample, each time heating it to a different maximum temperature up to $100 \mathrm{C}$, in order to follow the phase transitions of the low and high melting polymorphs. After each run, the sample was cooled to room temperature $(-25 \mathrm{C})$ by flowing air at a low rate through the sample block. This procedure allowed sufficient time for the cooling exotherm to develop reproducibly.

$X$-ray diffraction patterns were determined over the $2 \Theta$ range from 10 to 35 degrees with nickel-filtered, CuK $\alpha$ radiation $(\lambda=1.540 \AA$ ) on a diffractometer. ${ }^{*}$ The gutta-percha sample $(2.0 \times 1.5 \times 0.1 \mathrm{~cm})$ was mounted on a heated copper block $(4.5 \times 4.0 \times 0.9 \mathrm{~cm})$ which was inserted into the goniometer. Hot water from a constant temperature bath $\S$ was circulated through the block until the desired temperature was reached. A chromel-alumel thermocouple, imbedded under the surface of the sample, was used to monitor the sample temperature on a digital millivoltmeter.

\section{Results}

Four thermograms for heating rates of 5,10 , and $20 \mathrm{C}$ per minute are shown in Figure $\mathrm{I}$ with 
their corresponding cooling exotherms for the high melting polymorph of gutta-percha. There was no change in the major endotherm temperature of $57.5 \mathrm{C}$ with the varying heating rates. A heating rate of $20 \mathrm{C}$ per minute was chosen in subsequent runs because of the sharpness and the reproducibility of peaks.

The dependence of the size of the endotherm and peak temperature on the amount of the high melting polymorph present ( 5 -mg sample) is shown in Figure 2. For this sequence of DTA runs, the maximum temperature to which the sample was heated for each run did not exceed $65 \mathrm{C}$. This assured the formation of only the high melting polymorph upon cooling. The end temperature at which cooling was stopped and the next DTA run started was reduced from $49 \mathrm{C}$ to $39 \mathrm{C}$ in steps of approximately one-degree intervals (Fig 2, right column) in order to control the amount of the crystalline phase formed during each cooling cycle. With each successive step in lowering the cooling temperature, more crystalline high melting polymorph was formed, as indicated by the corresponding increase in the endotherm peak heights. An ac-

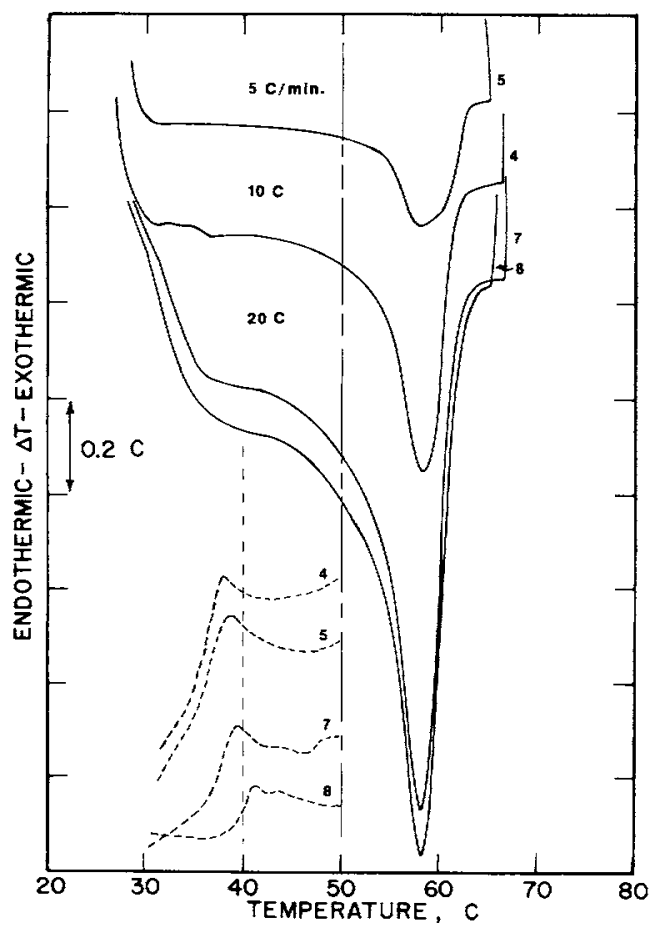

FIG 1. - DTA curves of gutta-percha at three rates of heating. The exotherms on subsequent cooling are shown with broken lines ( - - - ).

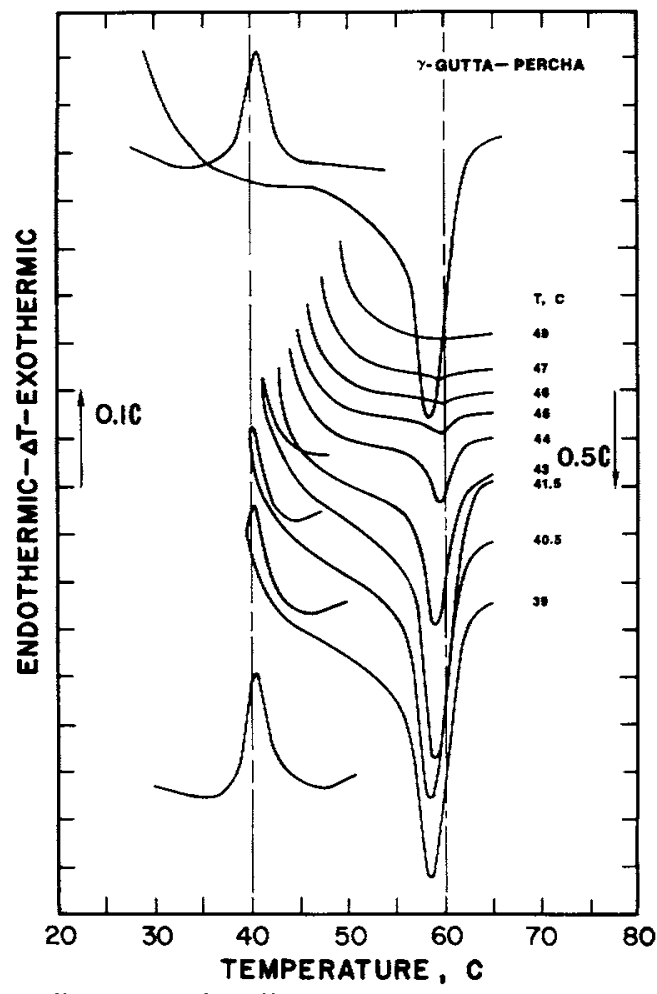

FIG 2. - The effect of cooling temperature on endo- and exotherms of the high melting polymorph. The scale of the $\mathrm{T}$ axis is $0.1 \mathrm{C}$ for the exotherms and $0.5 \mathrm{C}$ for the endotherms.

companying shift in the peak temperature of the endotherm from $60 \mathrm{C}$ down to $57.5 \mathrm{C}$ was observed which was attributed to increased crystallinity. A cooling exotherm at $40 \mathrm{C}$ (crystallization temperature) corresponds to the en. dotherm at $57.5 \mathrm{C}$. The peak areas represent the relative proportions of crystalline phase present. Integration of the peak areas resulted in a linear relationship with the corresponding peak temperatures $\left(T_{e n}\right)$. An analysis of linear regres$\operatorname{sion}^{8}$ that assumed no imprecision in values of peak temperature resulted in:

$$
\text { Peak area }=152-2.56 \mathrm{~T}_{e n} .
$$

A correlation coefficient ( $r$ ) of -0.996 was obtained. The critical value of $r$ - which the hypothesis of independence of peak area and $T_{e n}$ could be rejected was 0.950 at the $95 \%$ level of confidence.

Some typical thermograms have been reproduced in Figure 3. In this figure, the cooling curves (exotherms) are indicated by broken 


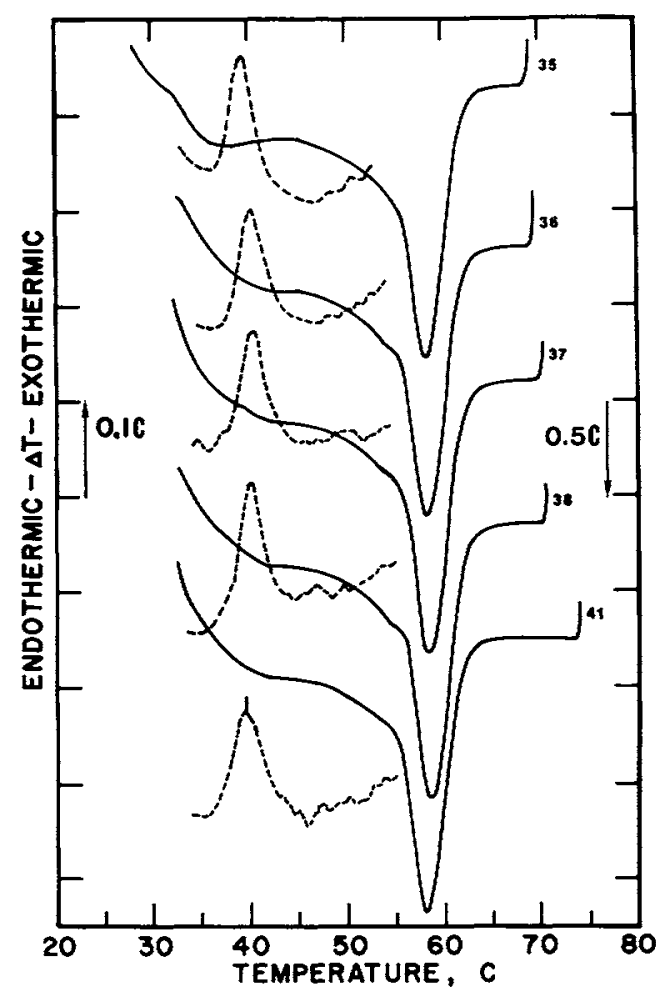

FIG 3a. - The effect of the maximum sample temperature on endotherms of high melting polymorph of gutta-percha. Cooling exotherms are drawn in broken lines ( - - - ). The maximum sample tem. perature increased from $68 \mathrm{C}$ to $74 \mathrm{C}$ for runs 35 to 41 .

lines intersecting the heating curves. The guttapercha sample, converted in the previous runs to the high melting polymorph, was subjected to a maximum sample temperature increasing from $68 \mathrm{C}$ to $75 \mathrm{C}$. The appearance of a small pip (very rapid release of energy) on the exotherm of the high melting polymorph (Fig 3a, run 41 , broken line) was the first indication that the low melting polymorph was crystallizing out simultaneously. Not until several runs later (Fig 3b, runs 43 and 45) where the sample was heated from $76 \mathrm{C}$ to $83 \mathrm{C}$, was a shoulder observed on the endotherm that could be attributed to the presence of the low melting polymorph.

The presence of both crystalline polymorphs was quite evident in samples where endotherms for both polymorphs were observed (Fig 3b, runs 46 to 48 ). The conversion of the high to low melting polymorph is illustrated in Figures $3 b$ and $3 c$ by the growth in size of the peak at about $48 \mathrm{C}$ and the reduction in size of the peak at about $58 \mathrm{C}$. The exotherms in Figure $3 \mathrm{~b}$ show two peaks, one for each polymorph formed. The peak of the low melting polymorph was 3 to 4 degrees lower in temperature and was also identifiable by the sharp pip.

The conversion to the low melting polymorph is shown to be completed in Figure 3c (runs 49 to 53) as indicated by the sharp, symmetrical exotherm at about $34 \mathrm{C}$. Because of the slow cooling rates, adequate time was available for small amounts of the high melting polymorph with an endotherm at $55 \mathrm{C}$ to crystallize out simultaneously with the low melting polymorph (runs 52 and 53). The high melting polymorph was produced upon cooling the specimen slowly through the temperature range of approximately $60 \mathrm{C}$ to $40 \mathrm{C}$. In order to eliminate the formation of the high melting polymorph when the low melting polymorph was desired, rapid cooling was required from temperatures above $80 \mathrm{C}$. This was achieved by quenching the sample in an ice bath, so that

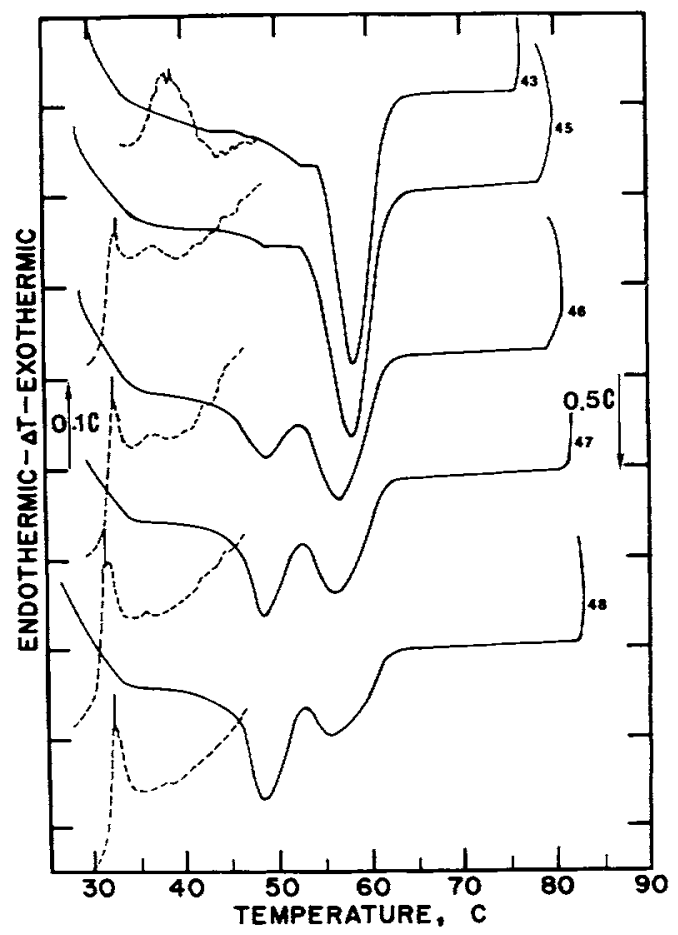

Fig $3 b$. - The effect of maximum sample temperature on the conversion of the high to low melting polymorph of gutta-percha. The temperature was increased from $76 \mathrm{C}$ to $83 \mathrm{C}$ for runs 43 to 48 . 
only the low melting polymorph crystallized below $35 \mathrm{C}$. On reheating, however, a new endotherm appeared between $35 \mathrm{C}$ and $37 \mathrm{C}$ which was not reversible and might have been caused by the relief of the internal stresses developed during quenching. When the sample was reheated through the endotherm peak to $40 \mathrm{C}$, cooled to room temperature and rerun, the endotherm did not reappear.

In order to complete the cycle and reconvert the low to high melting polymorph, the sample temperature was reduced to $70 \mathrm{C}$ in runs 54 and 55 (Fig 3c). The effect of the temperature drop is shown in Figure 3d (run 56), where endotherms appeared for both polymorphs. Further lowering of the temperature from $68 \mathrm{C}$ to $59 \mathrm{C}$ in the following thermograms (run 56 to 62) completed the conversion to high melting polymorph.

In order to identify the DTA endotherms with the correct polymorpic crystalline phase, $x$-ray diffractograms were made of the original

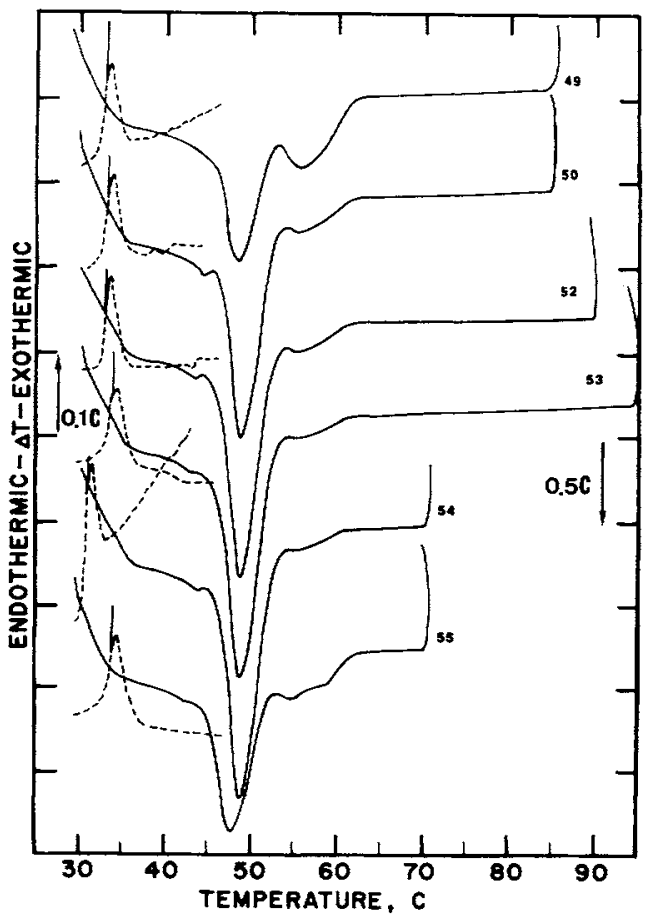

FlG 3c. - The effect of increasing the maximum heating temperature from $85 \mathrm{C}$ to $95 \mathrm{C}$ on the com. pletion of the transformation to the low melting polymorph (runs 49-53). In order to reverse the process, the maximum temperature was reduced to $70 \mathrm{C}$ in runs 54 and 55 .

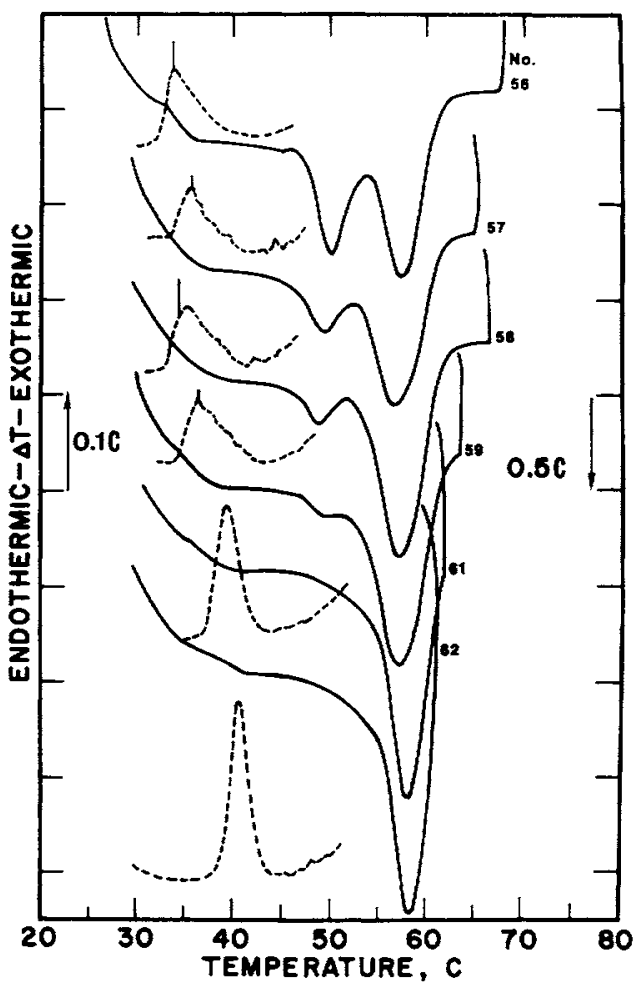

FIG $3 \mathrm{~d}$. - The effect of decreasing the maximum heating temperature from $68 \mathrm{C}$ to $59 \mathrm{C}$ on the transformation of the low to the high melting polymorph (runs 56-62).

(Fig 4, curve A) and the heat-treated samples (Fig 4, curves $C$ and $D$ ) of gutta-percha. Heat. ing a sample to $65 \mathrm{C}$ on a hot stage resulted in a broad $\mathrm{x}$-ray diffraction band characteristic of an amorphous, molten phase of gutta-percha (Fig 4, curve B). When the gutta-percha was heated to about $70 \mathrm{C}$ and cooled to room tem. perature, the high melting polymorph was produced (Fig 4, curve C) with a $58 \mathrm{C}$ endotherm (Fig 3a). Reheating the sample to $100 \mathrm{C}$ and cooling it to room temperature resulted in the high melting polymorph transforming back to the low melting crystalline phase (Fig 4, curve D) with a $48 \mathrm{C}$ endotherm (Fig 3c).

\section{Discussion}

Earlier observations have shown that two subsequent DTA runs on the same sample of gutta-percha did not yield identical curves. ${ }^{6.7}$ Quite often it was possible in the third run to reproduce the second run very closely when the sample was heated beyond $80 \mathrm{C}$. This indicated 
that the second DTA run served to heat treat the sample. The samples usually were heated above $80 \mathrm{C}$ with the result that the endotherm at $58 \mathrm{C}$ always diminished in size and the endotherm below $50 \mathrm{C}$ was either enhanced in size or split into two peaks. ${ }^{6.7}$

In order to relate the peak temperatures of the endotherms and exotherms to the maximum temperatures to which the sample was heated, Figures 5 and 6 were plotted. The dominant endotherm peak temperatures (solid points) appear to align themselves along the
$46 \mathrm{C}$ and $49 \mathrm{C}$ line for the low melting polymorph and along the $57.5 \mathrm{C}$ line for the high melting polymorph (Fig 5 ). The two dominant endotherms, as observed in Figures 3-b, c, and $\mathrm{d}$ and plotted as half solid points in Figure 5 , indicate the presence of both polymorphs to a significant degree in the sample. The presence of a minor endotherm, indicative of very small amounts of a minor phase coexisting with a dominant polymorph, is indicated by open points.

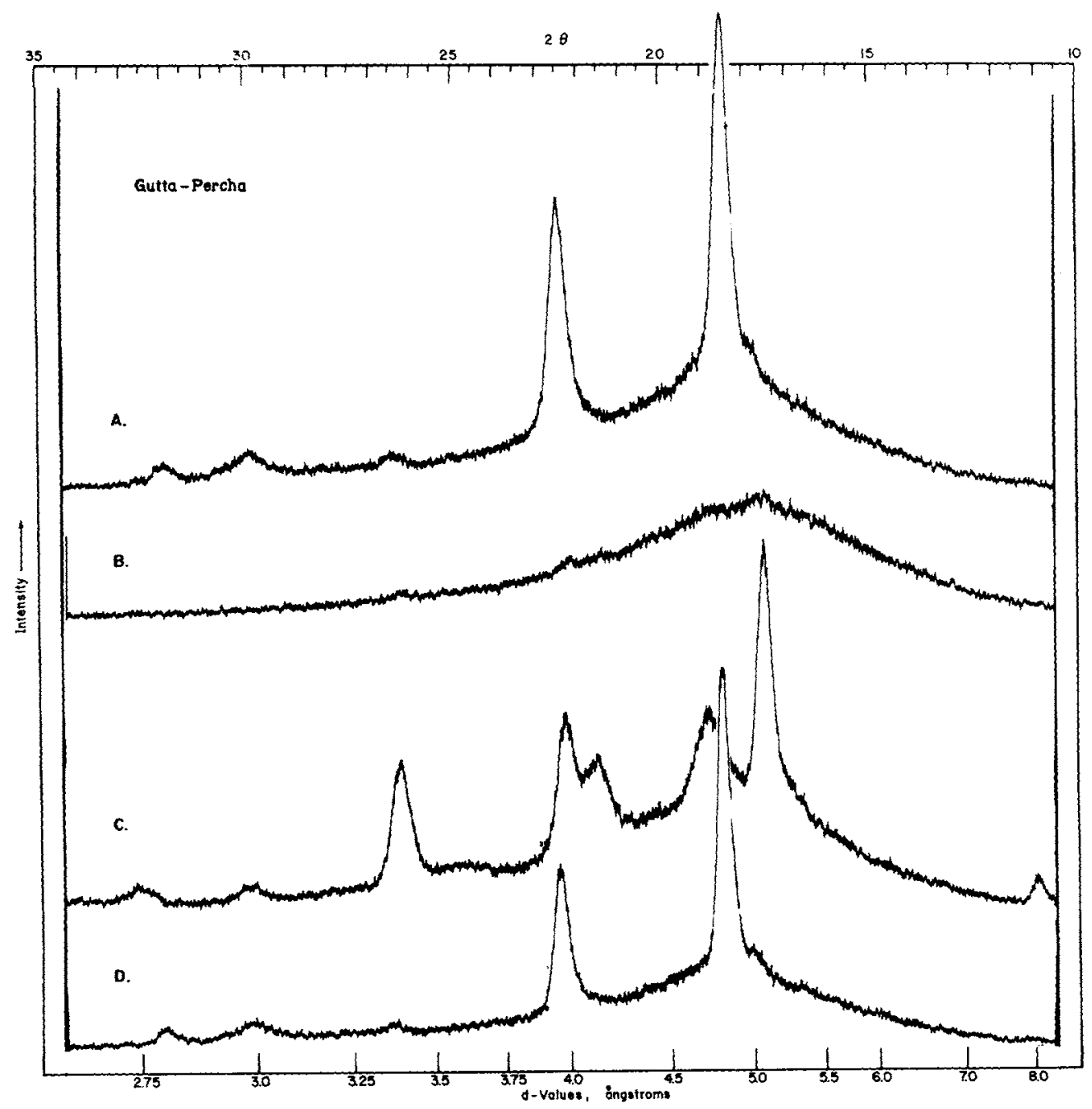

FIG 4. - X-ray diffractograms of gutta-percha samples. A) An original sample of gutta-percha in the low melting or beta crystalline polymorph, B) heated to $65 \mathrm{C}$ to an amorphous or molten state, C) heated to $70 \mathrm{C}$ and cooled to room temperature to transform the sample to the high melting or gamma crystalline polymorph, and D) reheated to $100 \mathrm{C}$ and cooled to room temperature to convert the sample back to the low melting crystalline polymorph. 


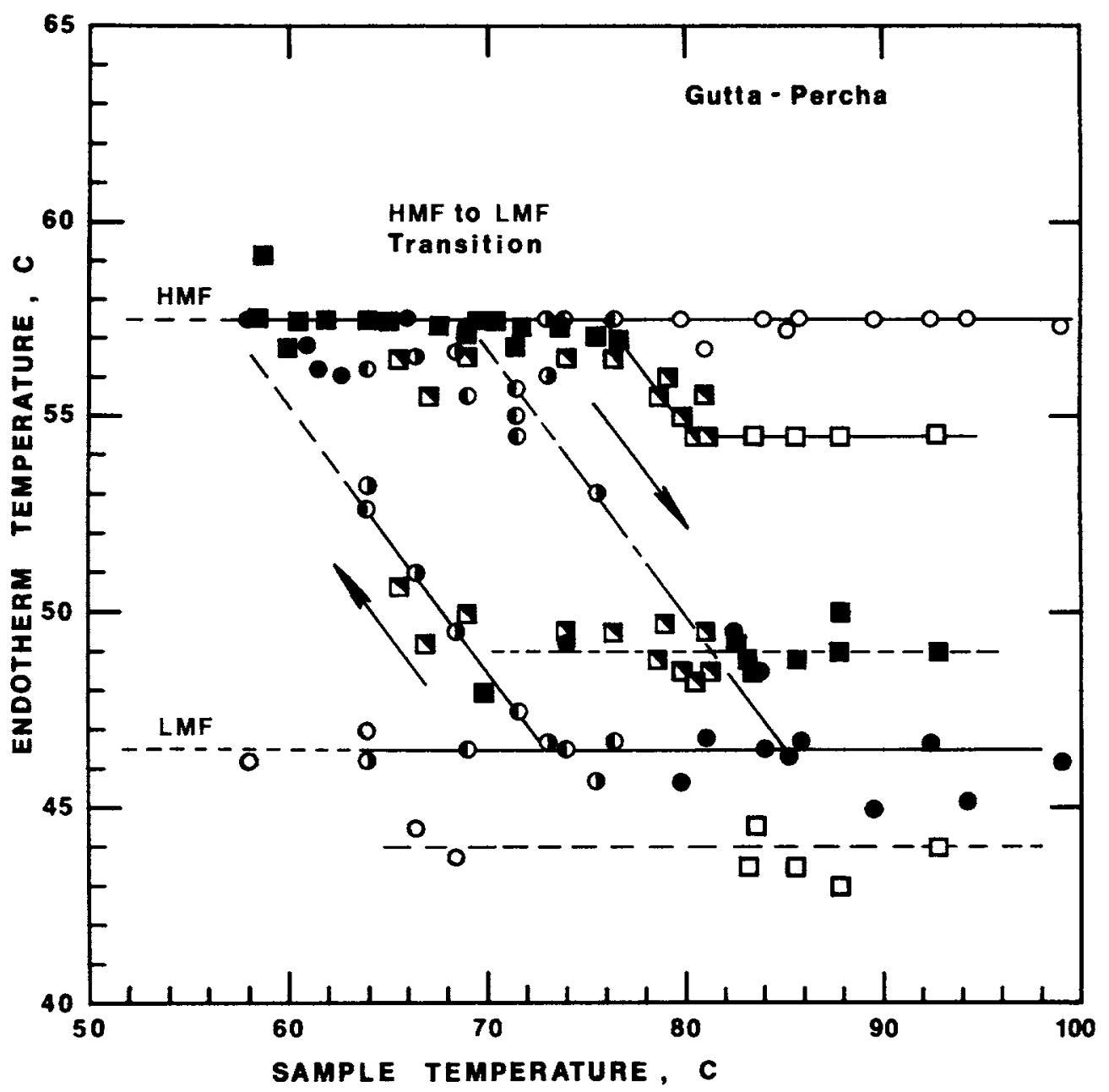

FIG 5. - Plot of endotherm peak temperatures as a function of maximum sample temperature. The dominant endotherms are indicated by solid points $(C$, $\mathbf{D})$, two coexisting peaks by half solid points $(\mathbf{O}, \mathbf{\square})$, and minor peaks by open points $(\bigcirc, \square)$. Circles rep.

Two independently obtained sets of data are plotted in Figure 5. The data from the first set of experiments are represented by circles and from the second set by squares. In the first set, the sample was cooled rapidly with a fast air flow to room temperature, whereas in the second set, the sample was cooled very slowly (about I C/min). Because of the slower cooling rate, these samples had adequate time in the $60 \mathrm{C}$ to $40 \mathrm{C}$ temperature range to form some of the high melting phase before crystallization of the low melting phase took place. The pres. ence of small amounts of the high melting poly. resent first set of data and squares the second set. The downward arrow indicates the conversion of the high melting to the low melting polymorph with increasing sample temperature. The upward arrow indicates the conversion in reverse direction.

morph with the low melting polymorph resulted in a slight elevation of the endotherm temperature of the low melting polymorph. As observed in Figure 5, the endotherms of the low melting polymorph leveled off at the $49 \mathrm{C}$ in. stead of the $46.5 \mathrm{C}$ line as in the first experiment. A corresponding $3 \mathrm{C}$ change can be observed in the endotherms of the high melting polymorph that show a change from $57.5 \mathrm{C}$ to $54.5 \mathrm{C}$. The high melting phase is only a minor constituent here. The arrows between the two horizontal lines indicate the direction of the endotherm temperatures with the change in sam- 
ple temperature. The downward arrow indicates the path of the transformation of the high melting polymorph into the low melting crystalline phase. This transformation occurs between temperatures of $70 \mathrm{C}$ and $80 \mathrm{C}$. Hysteresis was demonstrated by reversal of this transformation. The path of converting the low melting back into the high melting polymorph lowered the temperature by approximately $10 \mathrm{C}$.

Exotherms were recorded on cooling the sample after the heating cycle. They represent the crystallization temperature of the poly. morph. In Figure 6 , the peak temperatures were plotted as a function of the maximum temperature to which the specimen was heated. The exotherms followed the same pattern as the endotherms. In the first experiment, the guttapercha sample was heated first to $100 \mathrm{C}$ and then each subsequent time to progressively lower temperatures ending at about $63 \mathrm{C}$ (open squares). The exotherm temperatures remained at about $30 \mathrm{C}$ as the maximum sample temperature decreased to about $73 \mathrm{C}$. Further lowering of the sample temperature to $65 \mathrm{C}$

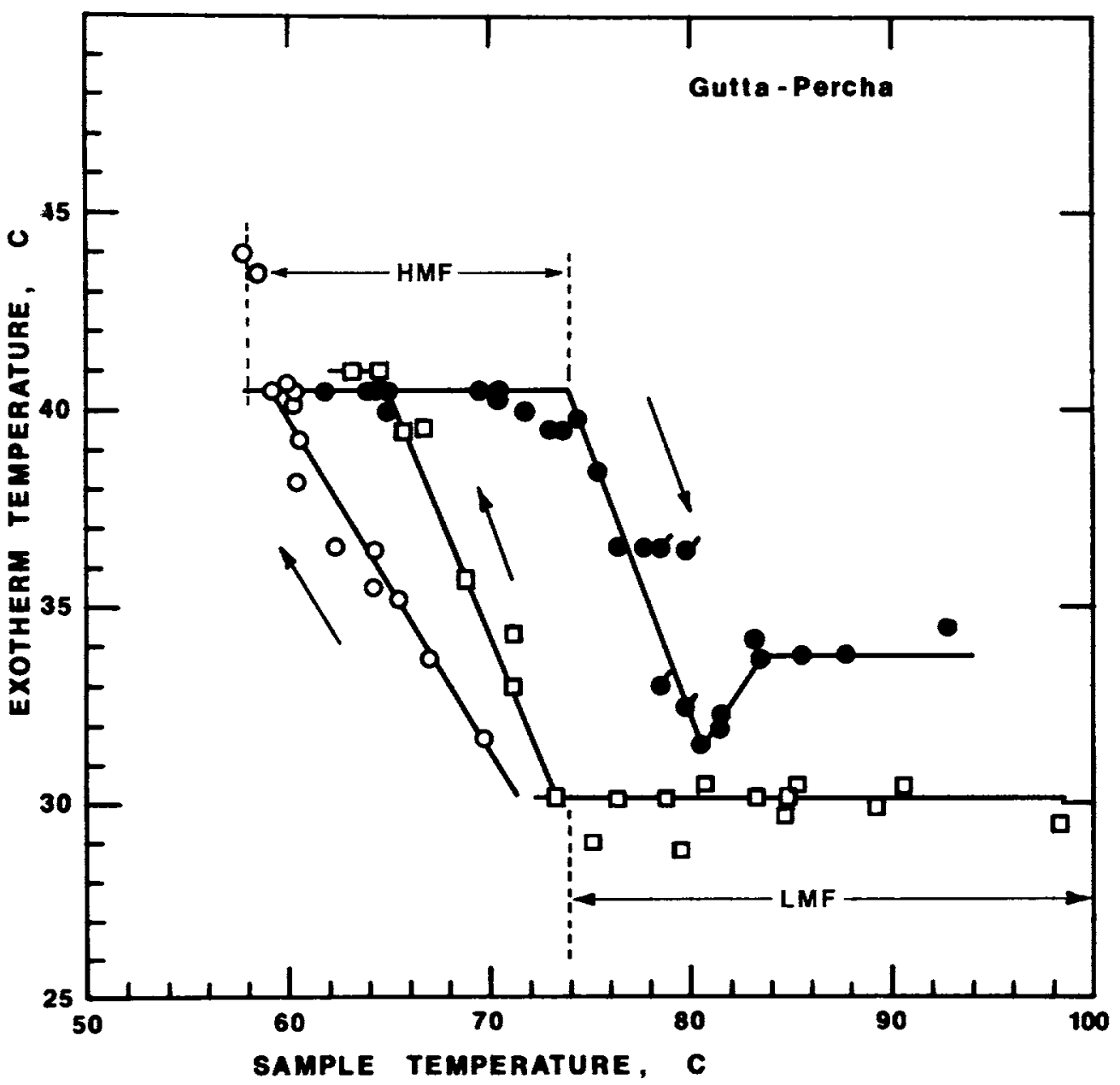

FIG 6. - Plot of exotherm peak temperatures as a function of maximum sample temperature. The ranges of crystallization for both polymorphs of gutta. percha are indicated. The intermediate slopes are the transition curves from one phase to the other. The arrows indicate the direction of the path. Open squares
( $\square$ ) represent the data from the first set of experiments. The data from the second set (Fig 3) are plotted as circles, with closed circles $(O)$ indicating conversion of the high melting to the low melting polymorph, and open circles $(O)$ indicating conversion back to the high melting polymorph. 


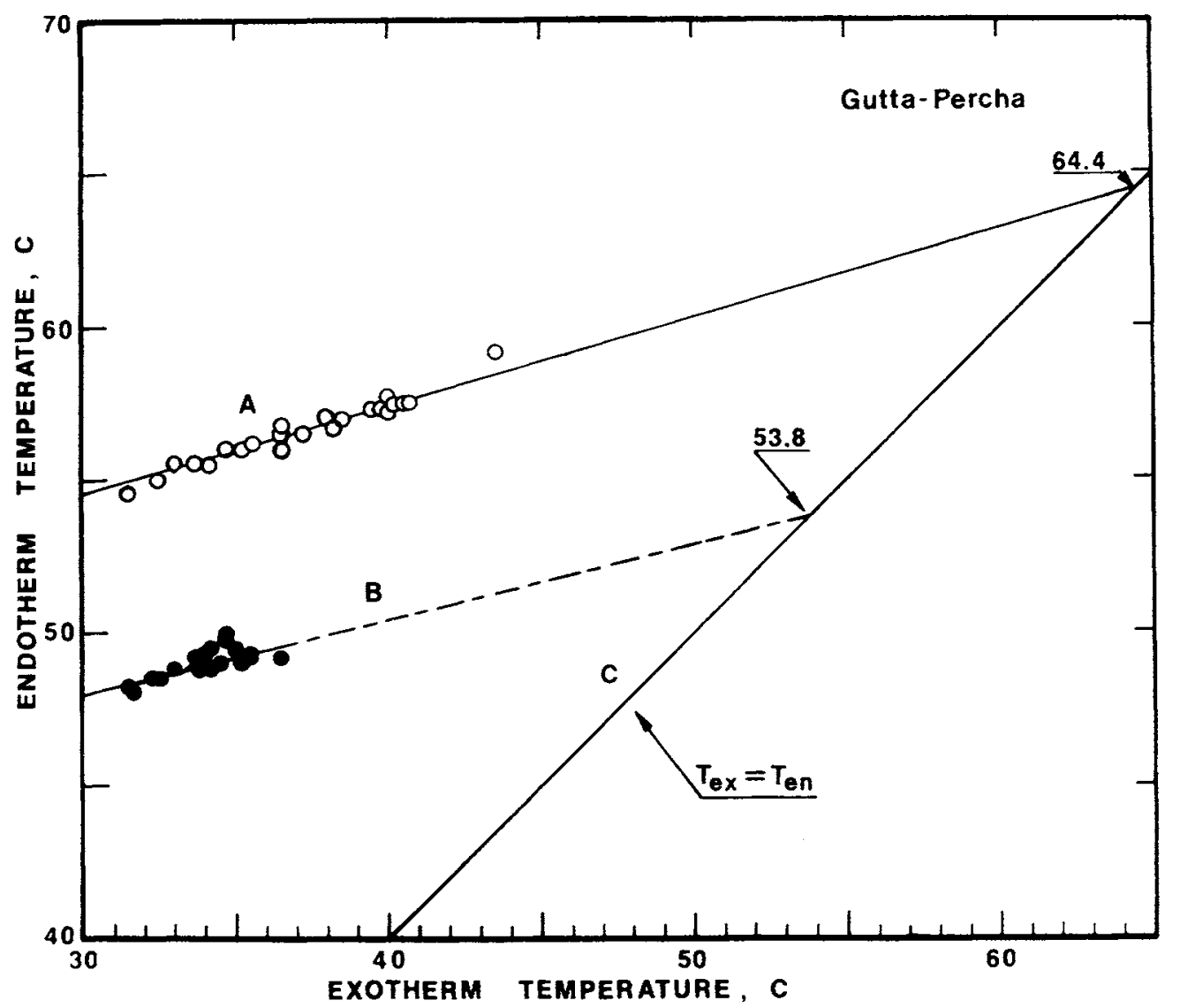

Fig 7. - Plot of endotherm peak temperatures (melting) determined experimentally as a function of exotherm peak temperatures (crystallization) for the

brought about the conversion of the low melt ing to the high melting polymorph. This cooling curve (open squares) was generated with the specimen cooled relatively rapidly. When a very slow cooling rate was used in the second experiment (circles), the exotherms followed a different path from the low melting to the high melting polymorph (open circles). Decreasing the cooling rate shifted the transformation path to lower sample temperatures.

To reverse this process and transform the high melting back to the low melting crystalline phase, the specimen was heated to increasingly higher temperatures (closed circles). The hysteresis loop, identical to that of the endotherms, was again displaced by the shift of the downward slope of the exotherm temperatures (downward arrow) by approximately 10 degrees to a higher sample temperature. Also a sudden high melting (A) and the low melting (B) polymorphs of gutta-percha. The isothermal line (C) is $T_{e x}$ equals $T_{e n}$.

elevation of the exotherm temperatures from $30 \mathrm{C}$ to $34 \mathrm{C}$ was observed in the sample temperature range of $80 \mathrm{C}$ to $84 \mathrm{C}$. This elevation of the exotherm temperature is analogous to the behavior of the endotherms at that sample temperature level and is probably caused by small amounts of the high melting phase present in the low melting polymorph. When the sample was heated to above $84 \mathrm{C}$ and cooled very slowly, the high melting phase had adequate time to crystallize before the low melting phase began to crystallize. Thus, the phase transitions in gutta-percha are reversible. The high melting crystalline phase can be converted to the low melting phase and back again by simple control of the temperature to which the gutta-percha sample is heated. The paths of the two transitions, however, are not reversible because of the hysteresis. 
The endotherms obtained from the DTA runs (Fig 5) were essentially the melting tem. peratures of the gutta-percha polymorphs crystallized from the melt at the exotherm temperatures (Fig 6). The endotherm temperatures $\left(\mathrm{T}_{e n}\right)$ were plotted against the exotherm temperatures $\left(T_{e x}\right)$ in Figure 7 . This type of plot has been used previously to calculate the equilibrium melting points $\left(\mathrm{T}_{m}^{\circ}\right)$ of large crystals in which surface effects are negligible. ${ }^{9-11}$ The equilibrium melting points can be used to derive thermodynamic parameters for the crystalline polymorphs; however, this study was concerned only with the dynamic aspects of rapid DTA analysis and the bulk melting and crystallization phenomena of gutta-percha. Since crystallization did not occur isothermally because of continuous cooling through the exotherm, and the endotherm data were obtained at relatively fast heating rates $(20 \mathrm{C} / \mathrm{min})$, the melting endotherm data could not be extrapolated to yield equilibrium melting temperatures for the two polymorphs. Nevertheless, a straight line relationship was determined by linear regression ${ }^{8}$ for the high melting phase (A) to be:

$$
\mathrm{T}_{e n}=46.0+0.286 \mathrm{~T}_{e x,}
$$

and for the low melting phase (B) to be:

$$
\mathrm{T}_{\text {en }}=40.4+0.249 \mathrm{~T}_{\text {ex }} .
$$

The assumption that the peak temperatures were known with no imprecision was made. Correlation coefficients of 0.973 and 0.889 , respectively, were obtained for the preceding equations. Critical values of $r$ above which the hypothesis of independence of $T_{e n}$ and $T_{e x}$ could be rejected were 0.423 and 0.514 , respectively, at the $95 \%$ level of confidence. These equations extrapolated to the line, $T_{e n}=T_{e x}$ in Figure 7 yielded equilibrium or, in this study, the limiting melting endotherm temperatures of $64.4 \mathrm{C}$ for the high melting polymorph and $53.8 \mathrm{C}$ for the low melting polymorph of guttapercha. These values were each about ten degrees below the melting points obtained dilatometrically by Mandelkern. ${ }^{3}$ The linear dependence of the endotherm temperatures on the exotherm temperatures for the low and high melting crystalline polymorphs of gutta-percha show that the actual melting endotherm for either polymorph can occur at any temperature along the line and is determined by the crystallization temperature for that polymorph. This estimated crystallization temperature $\left(T_{m}^{o}\right)$ has been found to be greater than the directly observed melting temperatures. ${ }^{9-11}$

\section{Conclusions}

DTA curves of the low and high melting crystalline polymorphs of gutta-percha were determined. Heat treatment of the gutta-percha was used to thermally induce the formation of either or both polymorphs in the sample.

By raising the temperature of the specimen from $70 \mathrm{C}$ to $100 \mathrm{C}$ and cooling it to room temperature, the high melting polymorph was transformed into the low melting polymorph. During slow cooling, some high melting polymorph crystallized with the low melting polymorph. When the sample was quenched at $0 \mathrm{C}$, the high melting polymorph was eliminated. On heating to $60 \mathrm{C}$, the high melting form was the dominant polymorph produced.

In all analyses, the endotherm temperatures were found to be dependent on the exotherm temperatures of the preceding run which acted as a heat treatment for the sample. The endotherm temperatures were found to depend linearly on the exotherm temperatures of the polymorph.

The transitions between the low and high melting polymorphs in gutta-percha were found to be reversible, cyclic phenomena with hysteresis. Either of the polymorphs could be produced by simple control of the temperature of heat-treatment of the sample.

\section{References}

1. BunN, C. W.: Molecular Structure and Rubber-like Elasticity, I. The Crystal Structures of Beta Gutta-Percha, Rubber and Polychloro. prene, Proc Roy Soc A 180:40-66, 1942.

2. FISHER, DOROTHY.: Crystal Structures of Gutta-Percha, Proc Phys Soc 66:7-16, 1953.

3. Mandelkern, L.; Quinn, F. A.; and Roberts, D. E.: Thermodynamics of Crystallization in High Polymers: Gutta-Percha, $J$ Am Chem Soc 78:926.932, 1956.

4. TAKahashi, YaSUHIRO; Sato, TAKEFUMI; TADOKORO, Hiroyuki; and TANAKa YasuYuKi.: Crystal Structure of Alpha Gutta-Percha: Modification of the Constrained Least-Squares Method, J Polym Sci Polym Phys Ed 11:233-248, 1973.

5. SChilder, Herbert; GoOdman, Alvin; and ALDRICH, WinTHROP.: The Thermomechanical Properties of Gutta-Percha III. Determination of Phase Transition Temperatures for Gutta-Percha, Oral Surg 38:109-114, 1974.

6. Rootare, H. M.; Powers, J. M.; and Smith, R. L.: Thermal Analysis of Experimental and Commercial Gutta-Percha, $J$ Endodont 2:244-249, 1976 . 
7. Rootare, H. M.; Powers, J. M.; and SMITh, R. L.: Thermal Analysis of Dental Gutta-Percha, in Porter, R. S. and JOHNSON, J. F. (eds), Analytical Calorimetry. Volume 4, New York, Plenum Press, 1977, $251 \mathrm{pp}$.

8. University of Michigan, Statistical Research Laboratory: A Manual of Elementary Statistics Using MIDAS. Ann Arbor, Statistical Research Laboratory, 1975, $301 \mathrm{p}$.

9. Gopalan, M., and Mandelkern, L.: The Effect of Crystallization Temperature and Molecular
Weight on the Melting Temperature of Linear Polyethylene, J Phys Chem 71:3833-3841, 1967.

10. Lovering, E. G., and Wooden, D. C.: Transitions in Trans-1,4-Polyisoprene, $J$ Polym Sci (A-2) $7: 1639 \cdot 1649,1969$.

11. Lovering, E. G., and Wooden, D. C.: Equilibrium Melting Points of the Low-Melting and High-Melting Crystalline Forms of Trans1,4-Polyisoprene, J Polym Sci (A-2) 9:175-179, 1971 . 